\title{
Three-Mode Biomedical Signal Denoising in the Local Phase Space based on a Tensor Approach
}

\author{
K. Pukenas \\ Department of Information Science and Languages, Lithuanian Academy of Physical Education, \\ Sporto 6, LT-44221, Kaunas, Lithuania, phone: +370 37 302668,e-mail: k.pukenas@lkka.lt
}

\section{Introduction}

The task of noise reduction is a central theme in a wide variety of fields. As the biomedical signals and the random noise often have overlapping bandwidths, the conventional methods based on the spectrum analysis did not work well for this data. Due to its simplicity in implementation and efficiency in computation the nonlinear phase-space projection technique together with singular value decomposition or approximate joint diagonalization a set of time-delayed covariance matrices procedure is an essential tool in noise reduction [1-5], signal detection [7, 8] and biomedical signal processing [9] algorithms. Several phase space projection methods, based on subspace decomposition, were proposed for application to the problem of additive noise reduction in the context of phase space analysis - the global projections method [2], [5] and the local (nearest neighborhoods) phase spaces method [1-4], [6].The local projection approach project the data in the neighborhood onto the hyper-plane and bring the flow pattern deviated back to the real dynamics system [6]. This approach has achieved nice noise reduction effects and has been applied to the speech signals, biomedical signals, mechanical vibration signals, etc. The local models process data in the vicinity of local neighborhoods leading to more detailed and possibly more complex models in comparison with the global projection methods. On the other hand, the local projection noise reduction approach is influenced by the neighborhood selection greatly and usually, neighborhoods merge if all data are contaminated by large amounts of noise, therefore these methods performed well with small or moderate amounts of noise.

The objective of this paper is to investigate the denoising performance of an improved local projection noise reduction approach based on 2D model of neighbors. The neighborhood tensor of 2D neighbors - windows with several consecutive vectors of reconstructed phase-space is computed rather than neighborhood matrix of each vector. Tensor approach is compared with its matrix- valued counterpart, which requires stacking the $2 \mathrm{D}$ neighbors into one highly structured neighborhood matrix.

\section{Local Projection Noise Reduction Algorithm}

A noisy time series $\left\{x_{i}\right\}_{i=1}^{L}$ could be reconstructed to a $m$-dimensional phase space by selecting the embedding dimension $m$ and time delay $\tau$, each phase point in the phase space is defined by [10]

$$
\boldsymbol{x}_{i}=\left[x_{i}, x_{i+\tau}, x_{i+2 \tau}, \cdots, x_{i+(m-1) \tau}\right]^{T},
$$

where $i=1,2, \cdots, L-(m-1) \tau$, and $(\cdot)^{T}$ denotes the transpose of a real matrix. At $\tau=1$ the reconstructed phase space matrix $\mathbf{X}$ with $m$ rows and $M=L-m+1$ columns (called a trajectory matrix) is defined by

$$
\mathrm{X}=\left[\begin{array}{cccc}
x_{1} & x_{2} & \cdots & x_{L-m+1} \\
x_{2} & x_{3} & \cdots & x_{L-m+2} \\
\vdots & \vdots & \ddots & \vdots \\
x_{m} & x_{m+1} & \cdots & x_{L}
\end{array}\right]
$$

The process of finding the neighbors of each point $\mathbf{x}_{i}$ in phase space is the most expensive step in most nonlinear noise reduction algorithms. Usually, the near neighborhood of the reference point $\boldsymbol{X}_{i}$ is defined as

$$
\mathbf{N}_{i} \triangleq\left\{\boldsymbol{x}_{k}:\left\|\boldsymbol{x}_{k}-\boldsymbol{x}_{i}\right\|<\varepsilon, \quad 1 \leq k \leq M\right\},
$$

where $\varepsilon$ - the size of the neighborhood. It becomes a nontrivial problem to identify the correct neighbors if all data are contaminated by large amounts of noise. When the neighborhood radius is too small, the neighborhood is submerged in noise and the fitting direction of this region is nearly random. And while the neighborhood radius is oversized the attractor manifold was also distorted. The high dimension of the embedding space helps partly to identify neighbors also for rather high noise levels $[3,7]$. Furthermore, the neighborhood selection algorithm is proposed as follows: (i) find a given number $K$ of nearest neighbors rather than a neighborhood of fixed radius, (ii) define the near neighborhood of the each no overlapping or overlapping windows $\mathbf{X}_{n} \in \mathbb{C}^{m \times P}$ having $P$ columns 
$\left\{\mathbf{x}_{i}\right\}_{i=k}^{k+P-1}$ of the trajectory matrix rather than the near neighborhood of the each point $\mathbf{x}_{i}$. The similarity between two matrices $\mathrm{X}_{n}$ and $\mathrm{X}_{j}$ is defined by

$$
S_{n j}=\frac{\operatorname{tr}\left(\mathbf{X}_{n}^{T} \cdot \mathbf{X}_{j}\right)}{\operatorname{tr}\left(\mathbf{X}_{n}^{T} \cdot \mathbf{X}_{n}\right) \cdot \operatorname{tr}\left(\mathbf{X}_{j}^{T} \cdot \mathbf{X}_{j}\right)} .
$$

In consequence the defined neighborhood can be rewritten into a three-mode format

$$
\mathcal{N}_{n} \in \mathbb{C}^{K \times m \times P}
$$

where the three modes of tensor are neighbors mode (size of the neighborhood, i. e. number of neighbors), reconstructed phase-space mode (embedding dimension) and window mode (window length, i. e. number of vectors in the window). Finally, by transpose second and third modes, the neighborhood tensor can be defined as

$$
\mathcal{N}_{n} \in \mathbb{C}^{K \times P \times m} .
$$

In order to perform a decomposition of the neighborhood tensors and split the three mode data into two orthogonal subspaces - the signal and noise subspaces - the higher order singular value decomposition (HOSVD) $[11,12]$ is used. The HOSVD is preferred over other decompositions because it provides an orthonormal basis, allowing an extension of the well-known matrix subspace technique [11].The HOSVD of a three-way array (6) is given by

$$
\mathcal{N}_{n}=\boldsymbol{S}_{n} \times{ }_{1} \mathbf{U}_{n}^{(1)} \times{ }_{2} \mathbf{U}_{n}^{(2)} \times{ }_{3} \mathbf{U}_{n}^{(3)},
$$

where $\boldsymbol{S}_{n} \in \mathbb{C}^{K \times P \times m}$ is the core tensor, which satisfies the all-orthogonality conditions [10]

$$
\boldsymbol{S}_{n}=\mathcal{N}_{n} \times{ }_{1} \mathbf{U}_{n}^{(1) T} \times{ }_{2} \mathbf{U}_{n}^{(2) T} \times{ }_{3} \mathbf{U}_{n}^{(3) T}
$$

and $\mathbf{U}_{n}^{(i)} \in \mathbb{C}^{M_{i} \times M_{i}}$ are the unitary matrices of $i$-mode singular vectors for $i=1,2,3$. In (7) and (8), the notation $\times i$ corresponds to the scalar product along the $i$ th mode. It has been demonstrated in [12] that the estimation of the three singular matrices of a given three-mode array $\mathcal{N}_{n} \in \mathbb{C}^{K \times P \times m}$ can be performed by the estimation of left singular matrices of the three possible unfolding matrices, obtained by stacking sub arrays in large matrices

$$
\mathbf{N}_{n}^{(1)} \in \mathbb{C}^{K \times P m}, \mathbf{N}_{n}^{(2)} \in \mathbb{C}^{P \times m K}, \mathbf{N}_{n}^{(3)} \in \mathbb{C}^{m \times K P} .
$$

This is to say that these unfolding matrices can be decomposed by singular value decomposition (SVD) into

$$
\mathbf{N}_{n}^{(i)}=\mathbf{U}_{n}^{(i)} \boldsymbol{\Sigma}_{n}^{(i)} \mathbf{V}_{n}^{(i) T} .
$$

The rank of a three-mode array can be defined as $\operatorname{rank}\left(r_{1}, r_{2}, r_{3}\right)$, composed of the ranks of unfolding matrices [11], i.e. $r_{i}=\operatorname{rank}\left(\mathbf{N}_{n}^{(i)}\right)$. Similarly to $2 \mathrm{D}$ arrays, subspace methods for three-mode arrays are based on a rank approximation of the HOSVD. Consider three-mode array (6) and its decomposition into two three-mode arrays

$$
\mathcal{N}_{n}=\mathcal{N}_{n s}+\mathcal{N}_{n n},
$$

where $\mathcal{N}_{n s}$ describes the signal subspace and $\mathcal{N}_{n n}$ the noise subspace. $\mathcal{N}_{n}$ can be expressed in terms of an "economy size" HOSVD in the following way $[11,12]$ :
$\widehat{\mathcal{N}}_{n s}=\mathcal{N}_{n} \times{ }_{1} \mathbf{U}_{n s}^{(1)} \mathbf{U}_{n s}^{(1) T} \times{ }_{2} \mathbf{U}_{n s}^{(2)} \mathbf{U}_{n s}^{(3) T} \times{ }_{3} \mathbf{U}_{n s}^{(3)} \mathbf{U}_{n s}^{(3) T}$,

where matrices $\mathbf{U}_{n s}^{(i)} \in \mathbb{C}^{M_{i} \times q_{i}}$ are obtained by keeping the first $q_{i}$ singular vectors $(i=1,2,3)$, associated with the signal subspace. The values $q_{i}$ are chosen by finding an abrupt change of slope in the curves of three-mode singular values. Actually, the matrices

$$
\mathbf{P}_{\boldsymbol{i}}=\mathbf{U}_{n s}^{(i)} \mathbf{U}_{n s}^{(i) T}
$$

are the projectors of the three unfolding matrices. The equation (12) operates directly on the measurement data and is therefore termed the "direct data approach" [13]. In this work, we calculate the signal subspace based on the relation between the HOSVD-based subspace estimate and the SVD-based subspace estimate in the presence of noise [14]. SVD is performed on the matrix $\mathbf{N}_{n}^{(3) T} \in \mathbb{C}^{K P \times m}$, which contains all vectors of neighborhood stacked along the rows

$$
\mathbf{N}_{n}^{(3) T}=\left[\mathcal{N}_{n}\right]_{(3)}^{T}=\mathbf{U}_{n} \boldsymbol{\Sigma}_{\mathbf{n}} \mathbf{V}_{\mathbf{n}}^{T},
$$

where $\left[\mathcal{N}_{n}\right]_{(3)}$ denoted a matrix unfolding of the tensor $\mathcal{N}_{n}$ along the 3 th mode. Applying the 3-mode unfolding to the tensor $\boldsymbol{u}_{n s}$, that represents the HOSVD-based basis for the signal subspace estimate, and taking its transpose, authors [13] obtain

$$
\left[\boldsymbol{U}_{n s}\right]_{(3)}^{T}=\widehat{\mathbf{U}}_{n s}=\left(\mathbf{P}_{1} \otimes \mathbf{P}_{2}\right) \mathbf{U}_{n s}^{(3)},
$$

i.e. the matrix-based subspace estimate $\mathbf{U}_{n s}^{(3)}$ gets premultiplied by a Kronecker product of $\mathbf{P}_{1}$ and $\mathbf{P}_{2}$, which are the projection matrices (13) onto the subspaces spanned be the one-mode and the two-mode vectors of the tensor $\mathcal{U}_{n s}$. The signal subspace $\widehat{\mathcal{N}}_{n s}$ defined by matrix unfolding of the tensor $\left[\widehat{\mathcal{N}}_{n s}\right]_{(3)}$ along the last dimension can be expressed as

$$
\left[\widehat{\mathcal{N}}_{n s}\right]_{(3)}=\left[\mathcal{N}_{n}\right]_{(3)} \cdot \widehat{\mathbf{U}}_{n s} \cdot \widehat{\mathbf{U}}_{n s}^{T}
$$

Given a tensor as matrix object $\left[\widehat{\mathcal{N}}_{n s}\right]_{(3)}$, we can rearrange its entries back into a tensor $\widehat{\mathcal{N}}_{n s}$, i. e. rebuilt the original data structure and define the projected trajectory matrix for reference matrix of neighborhood. Finally, an enhanced one-dimensional signal is created from the new space, typically by time-aligning and averaging the columns of the trajectory matrix $\mathbf{X}_{s}^{(d)}$ (see [2] for more details).

\section{Denoising performance analyses from simulated data sets}

We had applied the reviewed methods to the denoising of an $x$ component of the Rossler system contaminated with additive white, Gaussian and independent from signal noise. The signals of Rossler system may be used for the simulation of some biomedical signals, having a pseudoperiodic character. The Rossler system was simulated having parameters $a=0,398, b=2$ and $c=4$. It has been argued that the SVD method can obtain better results for pseudoperiodic signals by over-embedding with time delay $\tau=1[3,7]$. Therefore, the embedding dimension of 
the reconstructed phase space $m=60$ (approximately one cycle of the attractor) and time delay $\tau=1$ for all signals were defined. Ten sequences (each 1000 points) are used for evaluating the performance of the denoising at various signal-to noise level (SNR). The neighborhood of each segment $n$ of trajectory matrix is a three-mode array $\mathcal{N}_{n} \in \mathbb{C}^{30 \times 10 \times 60}$, that has neighbors mode (the first 30 nearest neighbors are used for each reference phase window), window mode (number of vectors in the window - 10), and embedding mode (embedding dimension - 60), which by over-embedding at $\tau=1$ play role of temporally mode. After looking at several combinations of three-mode ranks for the HOSVD subspace method, we have chosen one with $\operatorname{rank}(2,2,2)$. In the following, we compared multiway tensor data denoising HOSVD method with its matrix-based SVD counterpart, where neighborhood matrix $\mathbf{N}_{n} \in \mathbb{C}^{K \cdot P \times m}$ contains all $K$ transposed neighbors matrixes $\mathbf{N}_{n k} \in \mathbb{C}^{P \times m}$ concatenated along the rows. In kind of criterion evaluating the performance of the denoising of the signals the relative mean square error (MSE) $\varepsilon$ between the normalized original signal $x$ and estimated signal $\hat{x}$ is used

$$
\varepsilon=\frac{\|x-\hat{x}\|^{2}}{\|x\|^{2}},
$$

where $\|\cdot\|$ is the Euclidean norm. Data processing and time and frequency analyses were performed using software written in Matlab (The MathWorks, Natick, MA).

Fig. 1 shows the difference between the results obtained with the traditional local subspace approach and with the HOSVD local subspace approach. We can see that the HOSVD local subspace approach would lead to a smoother wave form without high-frequency distortions than that of the traditional local subspace approach.
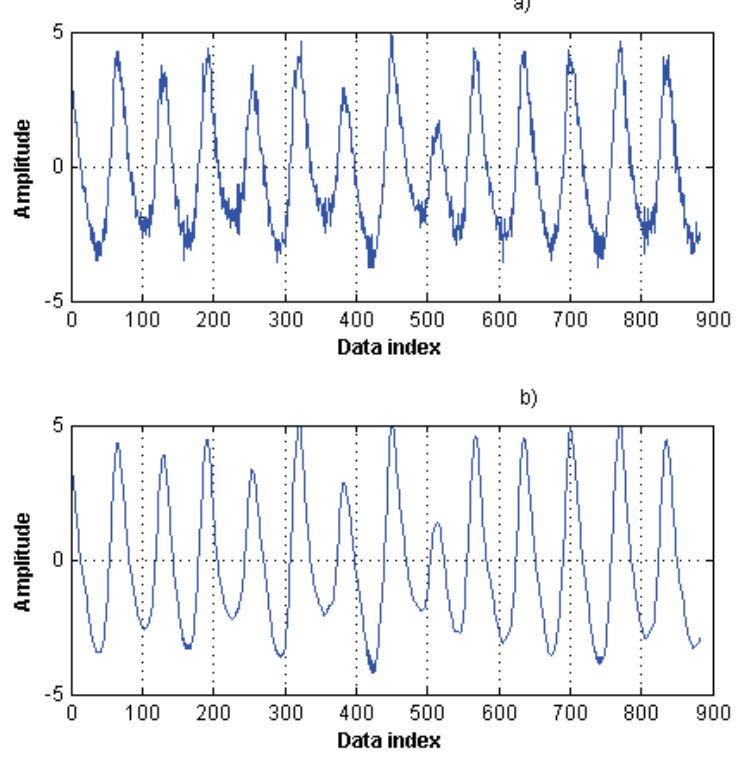

Fig. 1. Denoised signals of Rossler system at $S N R=0 d B$ : a) with traditional local subspace method, b) with the HOSVD local subspace method

Fig. 2 shows the averaged relative-mean-square errors between the original and denoised signals for HOSVD based technique applied to the neighborhood tensor and for
SVD applied on highly structured neighborhood matrix versus white Gaussian noise level.

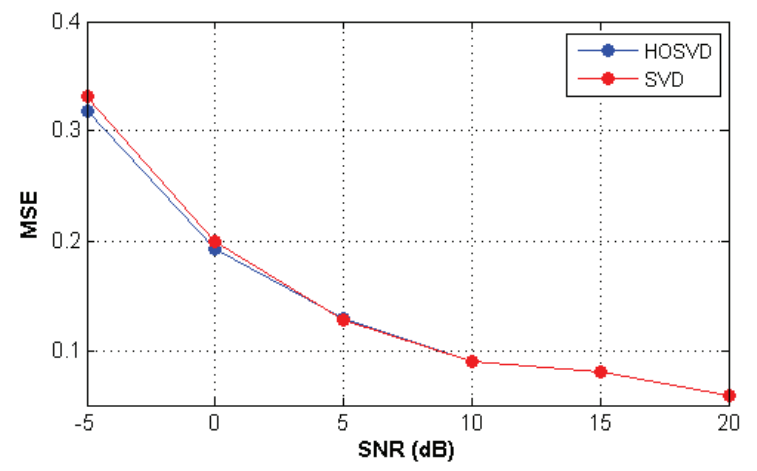

Fig. 2. The averaged relative-mean-square error versus white Gaussian noise level for denoising the signals of Rossler system with the HOSVD and SVD subspace methods

Fig. 3 shows the pulmonary arterial pressure signal contaminated with $5 \mathrm{~dB}$ additive white Gaussian noise and denoised signal with the proposed HOSVD based approach.
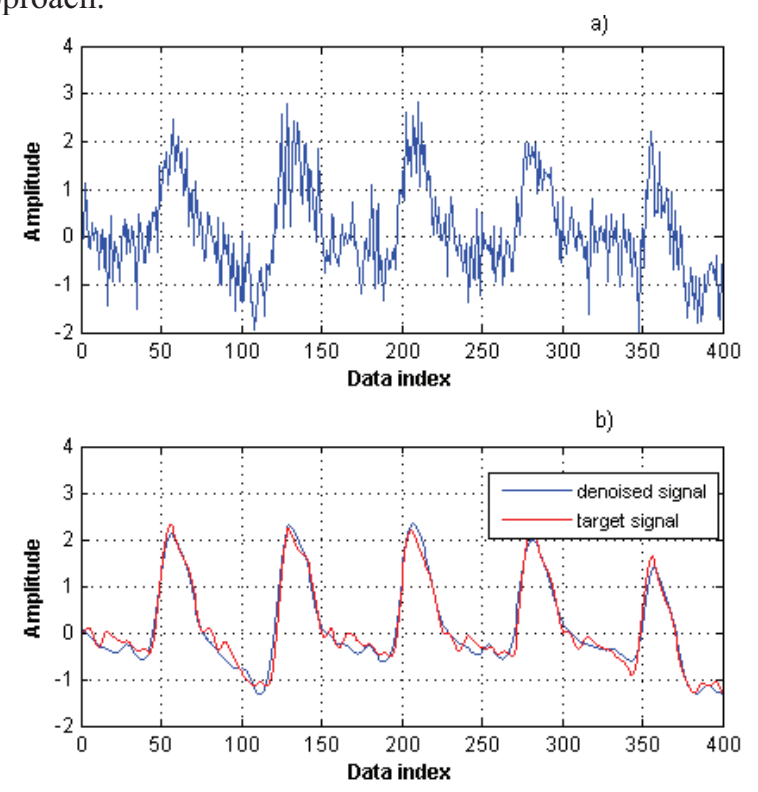

Fig. 3. Pulmonary Arterial Pressure signal, a) the raw data contaminated with $5 \mathrm{~dB}$ additive white Gaussian noise, b) target and denoised signals with the proposed approach

\section{Conclusions}

A simulation involving the synthetic and real biomedical signals shows the efficiency, in terms of noise reduction, of the proposed local projection noise reduction approach based on three-mode model of neighborhood compared to the well know local projection approach. Furthermore, for one dimensional signal, signal subspace estimated through the HOSVD of neighborhood tensors $\mathcal{N}_{n} \in \mathbb{C}^{K \times P \times m}$ approximately yields the same result as the signal subspace estimated by the applying a SVD on large neighborhood matrixes $\mathbf{N}_{n} \in \mathbb{C}^{K \cdot P \times m}$, containing all $K$ neighbors $\mathbf{N}_{n k} \in \mathbb{C}^{\cdot P \times m}$ concatenated along the rows. But tensor-based approach in comparison with the matrix approach is more robust to changes in numbers of singular vectors, where formed the signal subspace. The computational complexity of algorithms based on three- 
mode model of neighborhood and on highly structured neighborhood matrix is significantly higher than the traditional local subspace approach. Largely the computational time is defined by size of neighbor matrixes. Therefore, the number of consecutive vectors $p$ can't be too large, but approximately not less 10 - otherwise these approaches would degrade to the traditional local subspace approach.

\section{References}

1. Kostelich E. J., Schreiber T. Noise reduction in chaotic time-series data: A survey of common methods // Phys. Rev. E, 1993. - Vol. 48. - No. 3. - P. 1752-1763.

2. Johnson M. T. and Povinelli R. J. Generalized phase space projection for nonlinear noise reduction // Physica D, 2005. Vol. 201. - Iss. 3-4. - P. 306-317.

3. Sun J., Zhao Y., Zhang J., Luo X. and Small M.. Reducing colored noise for chaotic time series in the local phase space // Phys. Rev. E, 2007. - Vol. 76. - No. 2. - P. 026211-1-026211-6.

4. Hegger R., Kantz H., and Matassini L. Noise Reduction for Human Speech Signals by Local Projections in Embedding Spaces // IEEE Trans. Circuits Syst., I: Fundam. Theory Appl., 2001. - Vol. 48. - No. 12. - P. 1454-1461.

5. Luo X., Zhang J., and Small M. Optimal phase-space projection for noise reduction. // Phys. Rev. E., 2005. - Vol. 74. - No. 4. - P. 046711-1-046711-5.

6. Mingda W., Laibin Z., Wei L., Lixiang D. Research on the noise reduction for chaotic signals based on the adaptive local projection approach // 2010 International Conference on
Measuring Technology and Mechatronics Automation (ICMTMA), 2010. - Vol. 3. - P. 215-218.

7. Zhou C. T., Cai T. X., Cai T. F. Nonlinear real-life signal detection with a supervised principal components analysis // Chaos, 2007. - Vol. 17. - Iss.1. - P. 013108-1-013108-5.

8. Pukenas K. Nonlinear Detection of Weak Pseudoperiodic Signals hidden under the Noise Floor. // Electronics and Electrical Engineering. - Kaunas: Technologija, 2010. - No. 4 (100). - P. 77-80.

9. Kersulyte G., Navickas Z., Vainoras A., Gargasas L. Calculation of the Hankel Matrix Ranks of Electric and Haemodynamic Processes in the Heart // Electronics and Electrical Engineering. - Kaunas: Technologija, 2009. - No. 3 (91). - P. 43-48.

10. Kantz H., Schreiber T. Nonlinear Time Series Analysis. Cambridge University Press, Cambridge, 2003. -39 p.

11. Le Bihan N., Ginolhac G. Three-mode data set analysis using higher order subspace method: application to sonar and seismo-acoustic signal processing // Signal Processing, 2004; Vol. 84. - P. 919-942.

12. De Lathauwer L., De Moor B., Vandewalle J. A multilinear singular value decomposition // SIAM Journal on Matrix Analysis and Applications, 2000. -Vol. 21. - No. 4. P. 1253-1278.

13. Haardt M., Roemer F., Del Galdo G. Higher-Order SVDBased Subspace Estimation to Improve the Parameter Estimation Accuracy in Multidimensional Harmonic Retrieval Problems // IEEE Trans Signal Process, 2008. Vol. 56. - No. 7. - P. 3198-3213.

14. Thakre A. Haardt M, Roemer F, and Giridhar K. TensorBased Spatial Smoothing (TB-SS) Using Multiple Snapshots // IEEE Trans Signal Process, 2010. - Vol. 58. - No. 5. - P. $2715-2728$.

Received 20110214

K. Pukenas. Three-Mode Biomedical Signal Denoising in the Local Phase Space based on a Tensor Approach // Electronics and Electrical Engineering. - Kaunas: Technologija, 2011. - No. 3(109). - P. 49-52.

In this research, an improved local projection noise reduction approach with three-mode model of neighborhood is proposed. Firstly, one dimensional time series are embedded into a high dimensional phase space. Secondly, the neighborhood tensor of each reference no overlapping window with several consecutive vectors of reconstructed phase-space is computed rather than neighborhood matrix of each separate vector. Lastly, with the suggested model a higher order singular value decomposition (HOSVD) is performed on the neighborhood tensors to split the three mode data into two orthogonal subspaces: the signal and noise subspaces. Throughout the experiment, the effectiveness of the proposed method is validated with a noisy simulated data - the $x$ component of Rossler system and real biomedical signal contaminated with additive white Gaussian noise. Ill. 3, bibl. 14 (in English; abstracts in English and Lithuanian).

K. Pukẻnas. Trimatė biomedicininių signalų filtracija lokalioje fazinėje erdvẻje remiantis tenzorinės analizės duomenimis // Elektronika ir elektrotechnika. - Kaunas: Technologija, 2011. - Nr. 3(109). - P. 49-52.

Remiantis trimačiu artimiausių kaimynų modeliu, tiriamas signalų išskyrimo triukšmų fone lokalios fazinès erdvės metodas. Visų pirma rekonstruojama vienmatès laikinès eilutès daugiamatė fazinė erdvè. Toliau vietoj kiekvienam atraminiam rekonstruotos fazinės erdvès vektoriui artimiausių kaimynų matricos iš kelių gretimų rekonstruotos fazinès erdvès vektorių nustatomas kiekvienam neužklojamam langui artimiausių kaimynų tenzorius. Remiantis sudarytu modeliu, atliekama kaimynų tenzoriaus aukštesniojo laipsnio singuliariniu reikšmių dekompozicija, po kurios trimačiai duomenys padalijami i dvi ortogonalias suberdves: signalo ir triukšmų. Metodo efektyvumas tiriamas išskiriant iš adityviojo baltojo Gauso triukšmo chaotinį Rosslerio signalą, taip pat realų biomedicinini signalą. Il. 3, bibl. 14 (anglų kalba; santraukos anglų ir lietuvių k.). 